(C) Elsevier/INRA

Original article

\title{
The spread of parasitic sex factors in populations of Armadillidium vulgare Latr (Crustacea, Oniscidea): effects on sex ratio
}

\author{
T Rigaud, JP Mocquard, P Juchault \\ Université de Poitiers, Laboratoire de Biologie Animale, \\ URA CNRS No 1452, Génétique et Biologie des Populations de Crustacés, \\ 40, Avenue du Recteur Pineau, F-86022 Poitiers Cedex, France
}

(Received 24 May 1991; accepted 4 October 1991)

Summary - In the woodlouse Armadillidium vulgare, the basis of sex determination is under the control of heterochromosomes ( $\mathrm{ZZ}$ males and WZ females). However, in most populations, sex is determined by 2 maternally-transmitted parasitic sex factors (PSF). One is a Wolbachia-like bacterium (F), the other (f) is probably a sequence of $\mathrm{F}$ DNA unstably integrated in the $A$ vulgare genome. Both PSF are feminizing factors, which transform genetic males into functional neo-females $(\mathrm{ZZ}+\mathrm{F}$ or $\mathrm{ZZ}+\mathrm{f})$. The propagation of these PSF was investigated by introducing neo-females into artificial populations initially formed of genetic females. In the majority of these populations, $F$ bacteria were unable to spread, while $f$ seemed to have a higher invasive power. These results contrast with theoretical data: owing to the high transmission rate of PSF, their frequency should increase in populations where they have appeared. Based on the observation that PSF in populations have a behaviour similar to that of genes with selective advantages, a new approach was proposed to describe the spreading of PSF in limited-sized populations. This model showed that even a high transmission rate and in the absence of nuclear genes conferring resistance in $A$ vulgare, PSF can be lost from populations. The equilibrium probability of their disappearance depends on both the number of neo-females infesting the population and the transmission rate of PSF. These theoretical data, combined with the presence of genes repressing the feminizing effects of PSF, may explain part of the variability observed in sex determining systems and sex ratios of natural populations.

parasitic sex factor / sex ratio / simulation model / artificial population / Isopoda

Résumé - Propagation de facteurs sexuels parasites dans les populations d'Armadillidium vulgare Latr (Crustacé, Oniscoïde): conséquences sur le taux de masculinité. Chez le cloporte Armadillidium vulgare la base du déterminisme du sexe est hétérogamétique (mâles $Z Z$ et femelles WZ). Cependant, dans la plupart des populations naturelles, le sexe est déterminé par des facteurs sexuels parasites (FSP) transmis mater- 
nellement. Le premier d'entre eux est une bactérie $(F)$, le second (f) est probablement un segment de l'ADN de F intégré de façon instable au génome hôte. Ces deux FSP sont des facteurs féminisants qui transforment les mâles génétiques en néo-femelles fonctionnelles. La propagation de ces 2 facteurs a été étudiée en introduisant des néo-femelles dans des populations artificielles préalablement constituées de femelles génétiques. Dans la majorité de ces populations, la bactérie $F$ a été incapable de se propager, alors que le pouvoir invasif de $f$ semble être plus fort. Ces résultats sont en contradiction avec les données théoriques connues jusqu'alors: à cause de leurs forts taux de transmission, les FSP devraient envahir toutes les populations où ils apparaissent. $\dot{A}$ partir de la constatation que les FSP ont un comportement dans les populations similaire à celui de gènes sélectivement avantagés, une nouvelle approche théorique est proposée pour décrire la propagation de ces facteurs dans des populations à effectif limité. Ce modèle montre que, même lorsque le taux de transmission des FSP est fort, et en l'absence de gènes nucléaires de résistance chez $\mathrm{A}$ vulgare, ces facteurs peuvent ne pas s'implanter dans les populations. Leur probabilité de disparition à l'équilibre dépend à la fois du nombre de néo-femelles infestant la population et de leur taux de transmission. Ces données théoriques, combinées avec l'existence de gènes supprimant les effets féminisants des FSP, peuvent expliquer une part de la variabilité observée dans les mécanismes du déterminisme du sexe et du taux de masculinité dans les populations naturelles.

facteur sexuel parasite / taux de masculinité / modélisation / population artificielle / Isopode

\section{INTRODUCTION}

In populations of Isopoda Armadillidium vulgare where females produce offspring with a 1:1 sex ratio, sex is determined by the classical homo-heterogametic mode. Males are homogametic ZZ and females are heterogametic WZ (Juchault and Legrand, 1972). However, in several populations of this crustacea, sex ratios are often female biased and the majority of females regularly produce highly femalebiased broods (Juchault et al, 1980; Juchault and Legrand, 1981 a,b, 1989). It has been shown that, in these females, sex factors override the sex chromosomes' effects.

Two kinds of sex factors, whose effects are very similar, are known to exist. The first one is a symbiotic feminizing Wolbachia-like bacterium (F) carried by females located in the cytoplasm of all host cells, and especially in oocytes (Martin et al, 1973; Rigaud et al, 1991). Females harbouring $F$ have a male heterochromosomal composition (ZZ) and are thus neo-females $(\mathrm{ZZ}+\mathrm{F})$ (Juchault et al, 1980). The F bacteria are maternally transmitted. Infected oocytes evolve into neo-females or more rarely into intersexual types and the rare males arise from eggs free of $F$. It is experimentally possible to infect F-free $A$ vulgare by inoculation with tissue extracts from neo-females harbouring F. According to Bull's definition (1983), F could be called a cytoplasmic sex factor that inhibits the male nuclear genes. The second sex factor (named $\mathrm{f}$ ) is also able to transform genetic males into neo-females $(\mathrm{ZZ}+\mathrm{f})$ and is primarily maternally-transmitted. However, paternal transmission of f may occasionally be observed, but experimental horizontal transmission of this factor is impossible (Legrand and Juchault, 1984). The precise nature of $f$ remains 
unknown, but genetic and physiological data suggest that it might be a segment of $F$ bacterial DNA integrated in the isopod genome, with unstable behaviour (Legrand and Juchault, 1984). Taking into account the nature of $F$ and the origin of $f$, these 2 factors could be called "parasitic sex factors" (PSF). The extension of the term "parasitic" for a DNA segment has been used by Hickey (1982), in a model on the origin of sex.

Numerous abnormal sex ratios are known to exist in animals, but few of them are due to PSF: in both Amphipoda Orchestia gammarellus and Gammarus duebeni, PSF are related to Protozoa (Bulnheim, 1978; Ginsburger-Vogel et al, 1980). In the haplodiploid insect Nasonia vitripenis, sex is thought to be under the control of cytoplasmic microorganisms (Werren et al, 1981; Skinner, 1983).

In Armadillidium vulgare, natural populations show great variability in their sex ratios and in distribution of sexual factors (Juchault et al, 1980; Juchault and Legrand, $1981 \mathrm{a}, \mathrm{b}$ ): the 3 categories of females (WZ females, $\mathrm{ZZ}+\mathrm{F}$ and $\mathrm{ZZ}+\mathrm{f}$ neo-females) are mixed with very variable rates. It has been suggested that the appearance of PSF occurs later than the development of the heterochromosomal system (Legrand et al, 1987). Thus, following natural expansion in Europe from the Mediterranean basin after the last ice age, $A$ vulgare have spread over the whole world during the last few centuries subsequent to man's colonization of new territories (mainly in North America and a part of South America). Today, migration of this species is widely facilitated by man, by the exchange of foodstuffs between countries (Vandel, 1962), and mixing populations is often possible. The appearance of neo-females carrying PSF in an intact population (population consisting only of homo-heterogametic sex determined individuals) is therefore an interesting phenomenon to study, because this possibility seems to be the main factor for the dissemination of PSF.

In such a context, the theoretical evolution of sex determining mechanisms can be computed from the models of Bull (1983) and Taylor (1990). These models assume that, in a panmictic population, the frequency $(p)$ of neo-females harbouring PSF from one generation $n$ to another is:

$$
p_{n+1}=p_{n} \cdot \frac{T}{1-m} \quad \text { for } p_{n} \ll 1
$$

where $T$ is the proportion of neo-females in broods of $p_{n}$ neo-female mothers, and where $1-m$ is the proportion of females in broods of genetic females. PSF then increase in the population only if $T>1-m$ and, in the case of a ZZ/WZ homoheterogametic system, it invades the population by inducing the disappearance of the genetic females.

In all natural populations of $A$ vulgare, the average value of $T$ was between 0.6 and 0.8 for both $\mathrm{ZZ}+\mathrm{F}$ and $\mathrm{ZZ}+\mathrm{f}$ neo-females. With such values, the high variability in natural populations is surprising, and we wonder why PSF are not the only sexfactor in populations where they are present, because in theory the appearance of PSF induces the elimination of the $\mathrm{W}$ chromosome.

In this paper, we discuss the probability of survival and spreading of PSF when $\mathrm{ZZ}+\mathrm{F}$ or $\mathrm{ZZ}+\mathrm{f}$ neo-females appear in intact populations. We first created some artificial populations in the laboratory, then a theoretical simulation of the phenomenon was computed. 


\section{MATERIAL AND METHODS}

Test animals came from 3 strains sampled in nature and reared in the Poitiers laboratory for many years. $\mathrm{ZZ}+\mathrm{F}$ and $\mathrm{ZZ}+\mathrm{f}$ neo-females came respectively from Niort (France) and Rabat (Morocco), while WZ females came from Nice (France). Neo-females came from offspring where transmission of PSF was complete $(100 \%$ of neo-females in these offspring).

To simulate the appearance of foreign neo-females among genetic females, different kinds of artificial populations were created. The parental generation of each population consisted of 24 males and 24 females and breeding took place in a rectangular plastic tub $(63 \times 44 \times 22 \mathrm{~cm})$ containing moist soil and food in excess (carrots and chestnut leaves). The ratios between neo-females and genetic females $(\mathrm{ZZ}+\mathrm{F}$ or $\mathrm{ZZ}+\mathrm{f} / \mathrm{WZ}$ ) were: $3 / 21$ (low infestation rate of the population by the PSF) and 12/12 (high infestation rate). Males had the same origin and were in the same proportions as female categories. Each category of population was replicated 2 or 4 times. The tubs were kept at $20^{\circ} \mathrm{C}$ and under the natural photoperiod of Poitiers. Under such breeding conditions, 1 generation was obtained per year, but each female could produce more than 1 brood per generation.

In November, 6 months after the first hatchings, the sex ratio of 150 offspring randomly sampled in each tub was determined. The tub was then cleared and 48 animals from the sampling were then reared under the same conditions as their parents. The sex ratio in these 48 individuals conforms to the one determined with the 150 offspring. With this procedure, overlapping generations were avoided and each year in November, the size of the population was reduced to that at the outset. This artificial selection was made to simulate the mortality observed in nature (Aldabbagh and Block, 1981). After 3 generations, the rate of PSF was estimated by counting the different categories among 40 females randomly sampled in each population. The 3 categories of females were distinguished as follows (Juchault and Legrand, 1989): i), genetic females produced broods with a 1:1 sex ratio, regardless of rearing temperature and on the other hand, they could be masculinized by inoculation with an androgenic gland or by injection of the male hormone; ii), $\mathrm{ZZ}+\mathrm{f}$ neo-females could also be masculinized, but they produced highly femalebiased broods at $20^{\circ} \mathrm{C}$ and highly male-biased broods at $30^{\circ} \mathrm{C}$, after repression of the effect of $f$ at the latter temperature; iii), $\mathrm{ZZ}+\mathrm{F}$ neo-females were not sensitive to the masculinizing effect of the male hormone because of the bacterial presence.

The control series of artificial populations was made by breeding sisters of the $\mathrm{WZ}$ females, $\mathrm{ZZ}+\mathrm{F}$ and $\mathrm{ZZ}+\mathrm{f}$ neo-females placed in the tubs, by rearing their offspring separately, and then by breeding these offspring in the same way. Under such conditions, the mortality rate was very low and we estimated that the number of $\mathrm{ZZ}+\mathrm{F}$ or $\mathrm{ZZ}+\mathrm{f}$ neo-females produced in such broods reflected the primary transmission rate of the PSF. For the neo-female strains, mothers were chosen at each generation among broods including $100 \%$ of neo-females, to obtain a maximised estimate of the primary rate of transmission. It was possible to calculate a mean male ratio $(M M R)$ for the broods of females belonging to the same category, using a method described by Rigaud et al (1991). In one category of neo-females, the mean primary transmission rate $(T)$ of PSF then corresponds to $T=1-M M R$. 
In addition to these experiments, we wanted to test the evolution of the proportion of $\mathrm{F}$ in a population after horizontal transmission of this factor to genetic females. In order to obtain this horizontal transmission, ovaries from 10 $\mathrm{ZZ}+\mathrm{F}$ neo-females were ground and mixed with $1 \mathrm{ml}$ of physiological solution, and WZ females were inoculated with $1 \mu \mathrm{l}$ of this extract. Since recipient females transmitted $\mathrm{F}$ vertically, their offspring consisted of the following:

$$
\mathrm{WZ}+\mathrm{F}(q) \times \mathrm{ZZ}\left(\sigma^{\prime}\right) \rightarrow \mathrm{WZ}+\mathrm{F}(q)+\mathrm{ZZ}+\mathrm{F}(q)+\mathrm{WZ}(q)+\mathrm{ZZ}\left(\Im^{\prime}\right)
$$

It is known that the fraction of offspring infected by $F$ in broods of these females is the same as that in broods of ZZ+F neo-females (Juchault and Mocquard, 1989). We reared the $\mathrm{WZ}+\mathrm{F}$ females in artificial populations as described above, and these females were distinguished in the same way as the $\mathrm{ZZ}+\mathrm{F}$ neo-females.

Finally, to describe the behaviour of the 2 PSF when they are in contact with each other, $20 \mathrm{ZZ}+\mathrm{f}$ neo-females were inoculated with $\mathrm{F}$. These recipient neo-females were then paired and their offspring reared separately. After separation of the sexes in this $F_{1}, 2$ males and 2 females in each offspring (thus 80 animals) were placed in a plastic tub. This population was reared under the same conditions as the preceding ones, but no artificial selection was performed. After the fourth generation (3 years after the installation in the tub), the sex ratio was determined in a sample of 150 individuals. Moreover, 40 neo-females were inoculated with male hormone to attest the presence or absence of $F$.

\section{RESULTS}

\section{Course of the frequency of parasitic sex factors (PSF) in artificial populations}

Figures 1 to 3 show both the course of the sex ratio and frequencies of PSF in artificial populations.

In populations containing $\mathrm{ZZ}+\mathrm{F}$ neo-females (fig 1a,b), the general rule was that the fraction of males decreased during the first 2 generations, and then increased by about $50 \%$. After 3 or 4 generations, sex ratios of all these populations were not significantly different from 1:1 ( $\chi^{2}$ test non-significant in all cases). The neo-female frequencies during the third generation were very low, except in one population (fig 1b).

In populations with $\mathrm{ZZ}+\mathrm{f}$ neo-females (fig $2 \mathrm{a}, \mathrm{b}$ ), the course was very different from the preceding case. When the parental populations consisted of $50 \%$ neofemales, the male frequencies strongly decreased in the following generations. In $\mathrm{F}_{4}$, in the only evaluable population (high mortality appeared in the other one), this frequency increased slightly and stabilized at around $40 \%$ (fig $2 \mathrm{a}$ ). The proportion of $70 \%$ of neo-females (21/30 neo-females tested by breeding at $20^{\circ} \mathrm{C}$ and $30^{\circ} \mathrm{C}$ ) showed that invasion by $\mathrm{f}$ was in progress. In both populations where $\mathrm{f}$ infestation rate was low at the beginning of the experiment (fig $2 \mathrm{~b}$ ), 2 types of course were observed. On one hand, the fraction of males remained at about $50 \%$ during successive generations ( $\chi^{2}$ non-significant at each generation), and at the $\mathrm{F}_{3}$ generation, only $20 \%$ of females in the populations were neo-females ( 4 of the 20 

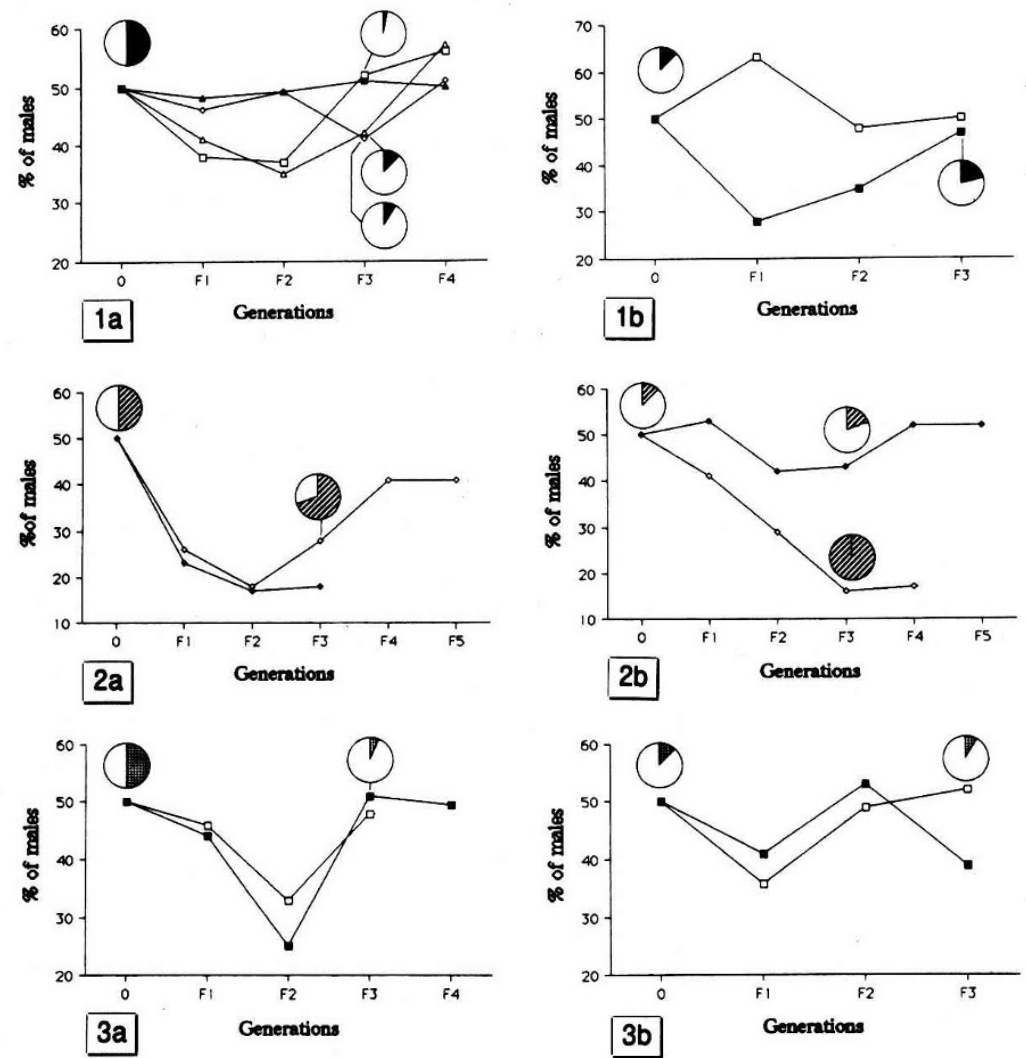

Fig 1. Male ratio course (lines) and course of PSF rates (pie charts) in mixed artificial populations. Populations harbouring genetic females and $\mathrm{ZZ}+\mathrm{F}$ neo-females.

Fig 2. Male ratio course (lines) and course of PSF rates (pie charts) in mixed artificial populations. Populations harbouring genetic females and $\mathrm{ZZ}+\mathrm{f}$ neo-females.

Fig 3. Male ratio course (lines) and course of PSF rates (pie charts) in mixed artificial populations. Populations harbouring genetic females and $\mathrm{WZ}+\mathrm{F}$ females. a: Parental generation consisted of 12 genetic females and 12 females with PSF, b: Parental generation consisted of 3 genetic females and 21 females with PSF. Each line represents one population, and the pie charts represent the PSF rate in the parental generation and in generation 3, for each evaluable population (in other populations, the females died after the tests). White area: genetic females - black: $\mathrm{ZZ}+\mathrm{F}$ neo-females - lined area: $\mathrm{ZZ}+\mathrm{f}$ neo-females - dotted area: WZ+F females.

surviving females after the tests). Stabilization of the sex ratio at $50 \%$ during the 2 generations following the $\mathrm{F}_{3}$ suggests that the PSF have disappeared. On the other hand, the percent of males strongly decreased during the first 3 generations, and then stabilized at about $18 \%$. In $\mathrm{F}_{3}$, no genetic female was observed among the 31 females tested, which showed that $f$ invasion in the population was complete. 
The course of composition of populations containing WZ females and Finoculated WZ females reminds us of those of mixed populations containing WZ females and $\mathrm{ZZ}+\mathrm{F}$ neo-females (fig $3 \mathrm{a}, \mathrm{b}$ ). In $\mathrm{F}_{3}$, the $\mathrm{F}$ factor tended to regress and the sex ratio became stabilized arround 1:1.

The $\mathrm{F}$ bacteria's disappearance could also be observed in $\mathrm{F}$-inoculated $\mathrm{ZZ}+\mathrm{f}$ neo-females. In the first generation, 18 of the 20 inoculated neo-females produced broods, in which the mean male ratio $(M M R)$ was equal to $9.6 \% \pm 3.6$. In theory, these breedings produced the following categories of individuals, with proportions dependent on $f$ and $F$ transmission rates:

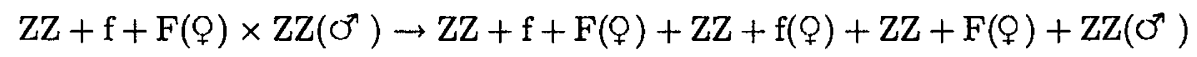

However, analysis of the artificial population made on individuals in this $F_{1}$ ( 2 males and 2 females in each brood) showed that, in the fourth generation, the percent of males was $31.2 \%$ and all females were masculinized by the male hormone (31/31 females tested). Thus, after 4 generations, the population consisted solely of $\mathrm{ZZ}$ males and $\mathrm{ZZ}+\mathrm{f}$ neo-females.

The $M M R$ in isolated broods of control WZ females, $\mathrm{ZZ}+\mathrm{F}$ and $\mathrm{ZZ}+\mathrm{f}$ neofemales in 3 generations allowed us to estimate the mean primary transmission rate of the PSF $(T=1-M M R$ ) (fig 4). In fact, PSF were transmitted by neofemales in a very variable manner, despite the fact that in each generation mothers came solely from male-free broods. The $\mathrm{F}$ transmission was more regular than the f one: for F, $T$ varied between 0.76 and 0.82 , while for $f, T$ varied between 0.53 and 0.8 . However, more precise analysis of these broods showed that mothers in each generation could be separated into 2 main categories: i), neo-females that highly or completely transmitted their PSF and which then conserved the maternal trait; and ii), neo-females that had not conserved the maternal trait, and which transmitted PSF more weakly (see as an example fig 5). Genetic females always produced offspring with sex ratios near 1:1 (fig 4).

\section{Simulation of the course of the frequency of PSF introduced in intact populations}

We sought to investigate the probability of spreading of PSF, after the appearance by migration of neo-females in some intact and finite-sized populations.

To establish the basis for this simulation, we started with the observation that PSF in Armadillidium vulgare have a behaviour in populations similar to that of genes with selective advantage. Indeed, if we consider that, with females producing offspring of the same size $(2 n)$, a genetic female produces $n$ females on average and a neo-female produces $n(1+c)$ neo-females. The parameter $c$ is a function of the transmission rate of PSF, and, if $c$ is positive, it represents the selective advantage of neo-females versus genetic females. This analogy allowed us to evaluate the probabilities of complete invasion or disappearance of neo-females harbouring PSF, after their appearance in a panmictic unharmed population.

The problem is quite different in a population with a finite size. To obtain such a population, we assumed that the number of mothers from one generation to the next is constant. Since paternal transmission of PSF is exceptional, males have been 


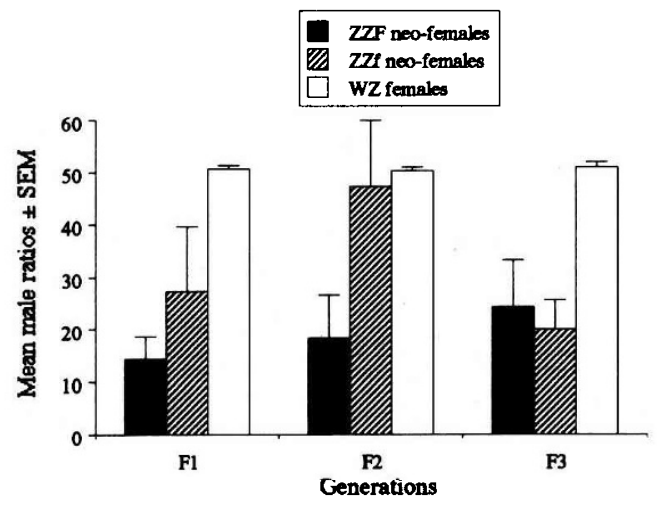

Fig 4. Mean male rates in isolated broods of sisters of females used in artificial populations. For neo-female strains in each generation, mothers were chosen in broods with full PSF transmission.
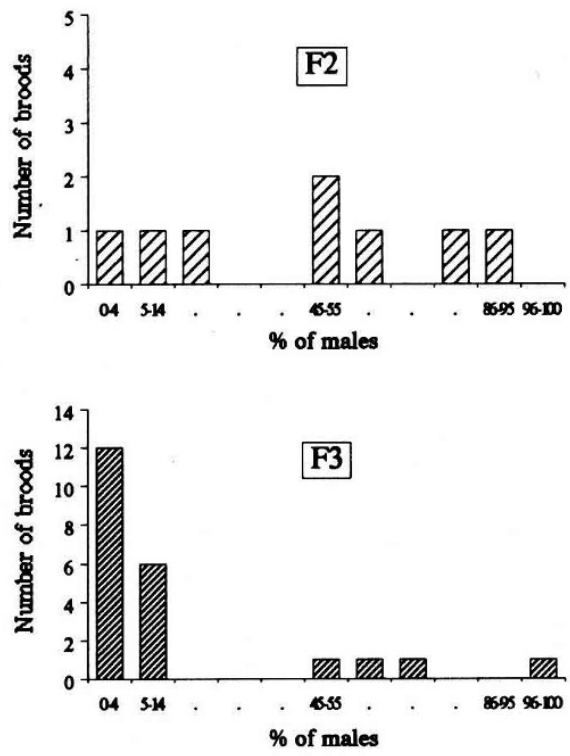

Fig 5. Percentage of male in broods of sisters of $\mathrm{ZZ}+\mathrm{f}$ neo-females used in artificial populations $\left(F_{2}\right.$ and $F_{3}$ generations).

ignored in the model. On the other hand, as one male could fertilize several females, we avoided giving values for rates of transmission equal to $100 \%$.

If in a population whose size is limited to $N$ mothers, there are $x$ neo-females in a generation, the rate of neo-females among daughters will be:

$$
p_{x}=\frac{(1+c) x}{(N-x)+(1+c) x}
$$


Since in each generation the size of the population is reduced to $N$ mothers, the mean number of neo-females will be $N p_{x}$, and the probability for obtaining $y$ neofemales $(y=0,1, \ldots, N)$ from one value of $x$ depends on a binomial law with parameters $N$ and $p_{x}$. The probabilities for all values of $x$ (from 0 to $N$ ) are given by the following matrix:

$$
|A|=\left[\begin{array}{ccccc}
p_{0,0}=1 & \ldots \ldots & p_{0, x}=\left(1-p_{x}\right)^{N} & \ldots & p_{0, N}=0 \\
\ldots & \ldots & \ldots & \ldots & \ldots \\
p_{y, 0}=0 & \ldots \ldots & p_{y, x}=\frac{N !}{N-y ! y !} \cdot p_{x}^{y} \cdot\left(1-p_{x}\right)^{N-y} & \ldots \ldots & p_{y, N}=0 \\
\ldots & \ldots & \ldots & \ldots & \ldots \\
p_{N, 0}=0 & \ldots \ldots & p_{N, x}=p_{x}^{N} & \ldots & p_{N, N}=1
\end{array}\right]
$$

The probabilities of obtaining from 0 to $N$ neo-females in the population from one generation to another are then given by the following equation:

$$
P_{g+1}=A \cdot P_{g}
$$

where $P_{g}$ for the $g$ generation is a vector composed of probabilities $p_{g, y}$ of one population containing $y$ neo-females $(y=0$ to $N)$, and where the generation 0 represents the starting conditions with the appearance of $x$ neo-females in the population (in fact, $p_{0, y}=1$ for $x=y$ and $p_{0, y}=0$ for any other values of $y)$.

Therefore, the simulation is that of the evolution of probabilities of obtaining from 0 to $N$ neo-females in the population, from one generation to another, for a given baseline number of $x$ neo-females (what we called "number of infesting neo-females") and for a given selective advantage $c$.

In order to compare this simulation with our preceding experiments, the size of the population was set at a low level ( $N=24$ females). Among all possible examples, here we reported the case where the number of infesting neo-females in the population was $x=3$, with 2 very different values for $c: c=0.05$ (which corresponds to a transmission rate of PSF equal to $52.5 \%$, ie, the lower mean rate observed in isolated broods), and $c=0.7$ (transmission rate of $85 \%$, the higher mean rate observed in isolated broods).

Despite the very different appearance in the 2 profiles (fig 6), the first finding that may be reported was a common trend which could logically be deduced from the model used: PSF progressed either toward fixation in the population (24 neofemales out of 24 females comprising the population), or toward disappearance (0 neo-females). An intermediate state of populations consisting of mixed genetic females and neo-females was merely a transient state which disappeared when the equilibrium was reached. In addition to differences between these profiles in values of probabilities at the equilibrium, the basic difference was the time necessary to reach this equilibrium. When $c$ was low (fig $6 \mathrm{a}$ ), after 35 generations the probability of fixation of PSF was equal to 0.15 and the probability of disappearance 0.67 . Between these 2 extremes, the probability of finding between 1 and 23 neo-females was about 0.01 . Moreover, the probability of the disappearance of PSF very rapidly reached 0.5 (in 10 generations), while the fixation was possible only after generation 12 , at a low level. The equilibrium (when the sum of probabilities was $>0.99$ ) was 

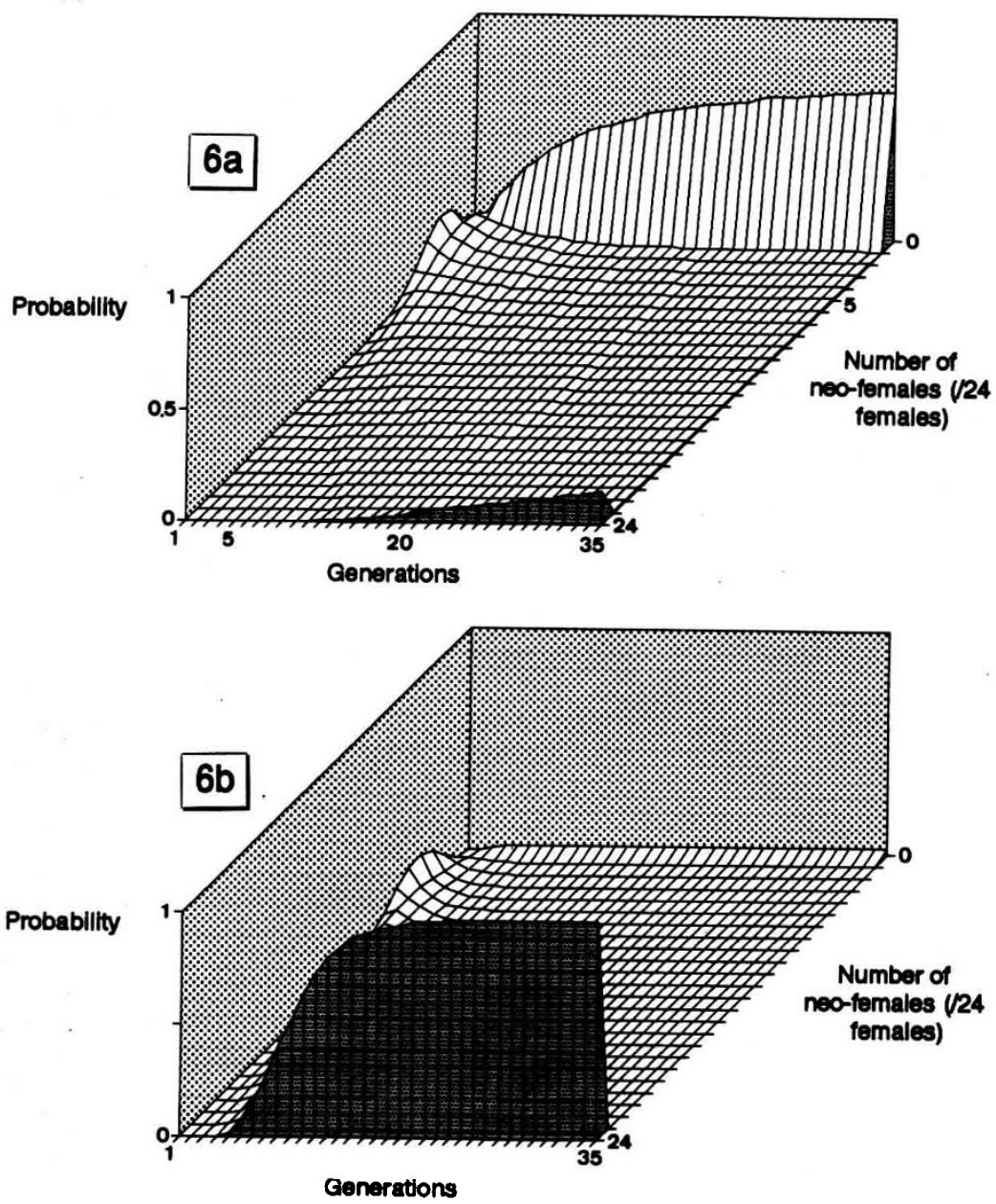

Fig 6. Surface plots of neo-female frequency versus generations, in 2 populations initially formed of 21 genetic females and 3 neo-females $-c=0.05$ (fig 6a) and $c=0.7$ (fig 6b).

then reached after 100 generations. In the opposite case, when $c$ was high (fig $6 \mathrm{~b}$ ), the equilibrium was reached very rapidly: 7 generations were enough to reach $3 \%$ for probability of disappearance of the PSF, while after 25 generations, the level for the probability of fixation was $97 \%$ and the equilibrium was then reached.

Another simulation was performed, using a variable $c$ value. If $c$ varied during the first 9 generations from 0.7 to 0.1 , and then stabilized, the probability progressed in a way that was very close to that where $c=0.7$ (fig 7): the probability of disappearance of the PSF after 35 generations was then much lower than the probability of fixation. However, it could be noted that the decrease in $c$ considerably slowed down the course toward the equilibrium. After 35 generations, 
the probability of fixation of the factor was equal to $77 \%$ and the probability of disappearance was about $9 \%$. Thus, there was still a $14 \%$ probability of finding some mixed populations containing both genetic females and neo-females. In this case, the equilibrium was reached after 85 generations.

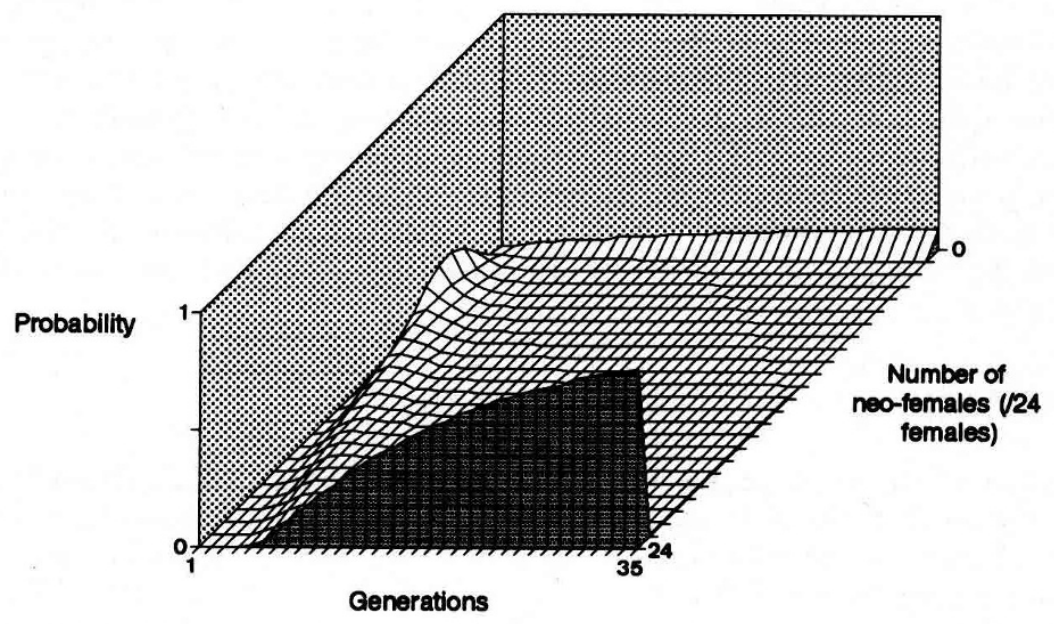

Fig 7. Same as in figure 6, but after $c$ decreased during the first 9 generations $=$ $0.7-0.7-0.6-0.6-0.5-0.4-0.3-0.2-0.1$, with stabilization at 0.1 .

The equilibrium probability of elimination of a PSF was computed for several values of $c$, as a function of the number of infesting neo-females in an intact population (fig 8). Calculations were performed for a population of 24 females and for an unlimited population. The probabilities of disappearance of the PSF were the same as for a mutant allele with a selective advantage:

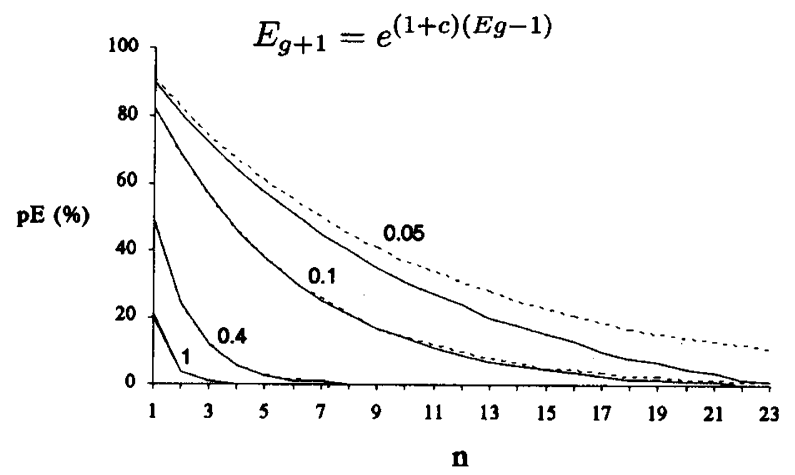

Fig 8. Probability of disappearance of the PSF at the equilibrium (pE) as a function of the number of neo-females infesting the population $(n)$, for 4 values of $c(c=0.05,0.1,0.4$, and 1). Solid line: population of 24 neo-females (stable number during generations), dotted line: unlimited population. 
As a general rule, the closer $c$ was to 0 , the higher was the probability of disappearance for the same number of infesting neo-females, and the more the limit where the probabilities of disappearance equal to 0 progressed toward high rates of infesting neo-females. It was interesting to note that for a transmission rate of PSF equal to $100 \%$ ( $i e$ for $c=1$ ), but with low infestation rate by neofemales, the disappearance of the PSF at the equilibrium could be considered. On the other hand, differences between limited and unlimited populations were only perceptible with low values of $c(<0.1)$. In these cases, differences were greater for high infestation rates by PSF: the probabilities of disappearance were then higher in a large population than in a small one. In the opposite case, when only one neofemale infested the population, a population of 24 females could be considered as unlimited, because the probabilities of disappearance of the PSF were very similar in the 2 cases.

\section{DISCUSSION}

Investigation of the mean primary transmission rates of the PSF in Armadillidium vulgare showed that $\mathrm{ZZ}+\mathrm{F}$ neo-females have a high rate of transmission of bacteria to their offspring, while mean transmission of $\mathrm{f}$ was more irregular. However, the mean transmission rate of PSF is always at least $50 \%$, which means that neo-females always produce on average more daughters than genetic females. The appearance of PSF in a population that contained only genetic females (intact population) should then theoretically lead to an increasing rate of neo-females in the population, and to the disappearance of genetic females. The rate of neo-females in the population should then equal the transmission rate of the PSF (Taylor, 1990).

However, analysis of artificial populations showed that in populations where the invading factor was $\mathrm{F}$, neo-females were often eliminated and, consequently, the male ratio reached $50 \%$ after a few generations. In contrast, the invasive power of $f$ seems to be higher, and the sex ratio in the populations generally progressed toward female-biased. However, failure of propagation of $f$ was possible in a population where infestation rate was low. These results may be compared to the spreading of symbiotic maternally-transmitted microorganisms in artificial populations of insects, although these microorganisms do not interfere with the sex determining mechanisms. In Sitophilus oryzae (Coleoptera), the endocytobiote (a Gram-negative bacteria) spreads rapidly in populations (Nardon and Grenier, 1989). This invasion is due to the fact that bacteria provide the insect with greater fertility and more rapid development. In the flour beetle Tribolium confusum, the rate of spread of a Rickettsiale responsible for reproductive incompatibility is a function of infestation rate in the population (Stevens and Wade, 1990). However, in this latter case, if the infestation rate is below 0.37 , the cytoplasmic factor is lost from the population. In these 2 examples, experimental observations follow the theoretical models.

The models previously used to describe the course of parasitic sex determination in Armadillidium vulgare do not consider the disappearance of $F$ or $f$ observed in artificial populations in the absence of any genetic control by the host, since the transmission rate of these PSF is higher than $50 \%$ on average (Bull, 1983; Legrand et al, 1987; Taylor, 1990). The model proposed in this paper considers that PSF of $A$ vulgare have the same behaviour as a selectively-advantaged gene when they 
appear in an intact population. This point was made with limited populations, but in fact we saw that the size of the population was only an important factor when the selective advantage of the PSF was low. In the latter case, the probability of the disappearance of the PSF is lower when the population is small. As the PSF tended to be either fixed or eliminated in the population, the presence of genetic females mixed with neo-females is then always a transient stage which may be of variable duration. When PSF transmission rate is low, or when it decreases progressively from one generation to the next, the time necessary to reach equilibrium is longer than when the transmission rate is high.

From this model, some courses observed in artificial populations may be explained, particularly in populations harbouring $\mathrm{f}$. It is still more difficult to explain the quasi-systematic elimination of $\mathrm{F}$, especially in cases where $50 \%$ of the females at the beginning of the experiment were $\mathrm{ZZ}+\mathrm{F}$ neo-females. In fact, events occur as if the transmission rate in the artificial populations was lower than the one observed in the isolated offspring, $i e$, as if the number of $\mathrm{ZZ}+\mathrm{F}$ daughters reaching adulthood was lower than the number of daughters produced just after the primary transmission rate of the PSF. Since $\mathrm{ZZ}+\mathrm{F}$ neo-females used in artificial populations and those used as control were sisters, the only notable difference between them is their competition or not with genetic females.

To explain the very frequent and rapid loss of $\mathrm{F}$ in the populations, we must assume that $\mathrm{ZZ}+\mathrm{F}$ neo-females showed a competitive disadvantage among genetic females, leading them to produce fewer daughters in their offspring. This phenomenon (under conditions of competition) may occur in 2 ways: either $\mathrm{i}$ ), the mortality of $\mathrm{ZZ}+\mathrm{F}$ daughters is higher than that of the WZ daughters; or ii), the $\mathrm{ZZ}+\mathrm{F}$ mothers overall produced fewer descendants, and thus fewer daughters. To date, no observation has confirmed the first hypothesis. On the contrary, it has been shown that the $\mathrm{F}$ endocytobiote, when inoculated into WZ females, depresses the growth of its new host. Moreover, in the Niort natural population, ZZ+F neofemales are smaller on average than $\mathrm{ZZ}+\mathrm{f}$ neo-females (Juchault and Mocquard, 1989). It is also known that fecundity in terrestrial isopoda is a linear function of the size of the female (Sutton et al, 1984; Juchault and Mocquard, 1989). Then, it could be suggested that, under conditions of competition, a decrease in fertility in neo-females harbouring the $\mathrm{F}$ bacteria might be the result of a difference in the rate of growth between the 2 categories of mothers. However, in view of our model, the number of $\mathrm{ZZ}+\mathrm{F}$ daughters do not have to be smaller than the number of WZ daughters to induce a disappearance of $F$ : reduction of the difference between these 2 values is sufficient to increase the probability of disappearance of the PSF. To explain such a phenomenon, it is difficult to postulate a difference between genotypes of the mothers, because $\mathrm{F}$ disappeared rapidly in populations consisting of $\mathrm{ZZ}+\mathrm{f}$ neo-females or $\mathrm{WZ}$ females inoculated with bacteria and their intact sisters.

The present study can provide'some answers to the problem presented in the introduction: why haven't PSF invaded the natural populations in which they are present, since their transmission rates are very high? First, we showed experimentally and theoretically that, even with a high transmission rate and in the absence of genetic control by the host, the invasion of PSF after their appearance in intact populations is not a systematic event. It appears that fixation of the $\mathrm{F}$ bacteria is more difficult than that of the factor. This last observation is in 
accordance with data obtained in natural populations, in which $F$ is less often observed than $f$ (Juchault and Legrand, $1981 \mathrm{a}, \mathrm{b}$ ). In light of these first results a part of the interpopulation variability observed in nature (both at the level of sex ratio and sex determining mechanisms) may be explained by the probability of fixation and disappearance of the PSF in populations.

However, if only this point of view is considered, a state of equilibrium must be theoretically reached, that is to say that populations must be composed sooner or later either solely of genetic females or of $\mathrm{ZZ}+\mathrm{F}$ or $\mathrm{ZZ}+\mathrm{f}$ neo-females. Such a condition in nature is very rare, since a majority of populations consist of a mixture of different categories of females, with very variables rates (Juchault and Legrand, 1981 a,b, 1989). An explanation of these observations goes beyond the scope of this study. This model and these experiments are only valid for isolated intact populations, infested by PSF, and which evolved in a closed world. Such a situation must be very rare in nature, since migrations between distant populations of $A$ vulgare are favoured by human contacts, and, on a more local scale, populations must be closely interconnected. Migration among populations should explain variability, since the former cannot evolve individually toward the equilibrium. Another factor that might explain the interpopulation variability is the variation in the transmission rate of the PSF. In natural populations, some nuclear genes of $A$ vulgare that override the expression of PSF are known to exist. The first one is a masculinizing gene $(M)$ that thwarts the feminizing effect of $\mathrm{f}$ (Legrand $e$ t $a l$, 1974; Juchault and Legrand, 1989). This gene (closely related to the restorer genes observed in the case of male-sterility in higher plants (Couvet et al, 1991) is present at a high rate in populations where sex is controlled by PSF. The other nuclear elements are genes conferring resistance to the cytoplasmic sex factor $F$ (Rigaud and Juchault, 1992). These resistance genes $(R)$ appear to be a polygenic system which prevents bacterial transmission to oocytes. These 2 categories of gene reduce the primary transmission rate, and then allow the production of a male rate high enough to enable fecundation of all the females. Theoretically, selection of such genes in populations is frequency-dependent (Bull, 1983; Taylor, 1990), but by migration, $M$ and $R$ genes could be introduced in all categories of populations. In our model, we saw that if the transmission rate of PSF decreased during successive generations (after selection of the $M$ gene in a population in the process of invasion, for example) the time to reach the equilibrium was longer than if the transmission rate was high. Such $M$ and $R$ genes could then enable preservation over a long period of mixed populations (genetic females + neo-females), but it is difficult to anticipate whether their incidence could reach a value high enough to prevent disappearance of genetic females. However, the presence of these genes might explain part of the variability observed in the sex ratio of natural populations when the fixation of PSF is reached. Taylor (1990) showed that the more a resistant allele is effective against effects of PSF, the more the equilibrium sex ratio is close to 1:1 for the same PSF transmission efficiency.

In fact, it is possible to say that the composition of natural populations observed at a given moment is simply a snapshot of a system in constant evolution, composed of transient populations that progress toward several types of equilibrium with different rates of speed. Some events such as the selection of restorer genes of the male sex, exchanges between populations and competition between the different 
categories of females may be the source of the wide variability in the population structure. Another mechanism able to increase this variability and which develops in parallel is the internal evolution of the sex determining mechanisms. Considering the model proposed by Legrand et al (1987), the continuous appearance in populations of the $f$ factor from the $F$ bacteria could still increase the probability of finding situations where different categories of females could be mixed.

\section{REFERENCES}

Al-Dabbagh KY, Block W (1981) Population ecology of a terrestrial isopod in two breckland grass heaths. J Anim Ecol, 50, 61-77

Bull JJ (1983) Evolution of Sex Determining Mechanisms. Benjamin Cummings Publ Co, Menlo Park, CA

Bulnheim HP (1978) Interaction between genetic, external and parasitic factors in sex determination of the crustacean amphipod Gammarus duebeni. Helgol Cuissens Meer, 31, 1-33

Couvet D, Atlan A, Belhassen E, Gliddon C, Gouyon PH, Kjellberg F (1991) Coevolution between two symbionts: the case of cytoplasmic male-sterility in higher plants. In: Oxford Surveys in Evolutionary Biology (Futuyama DJ, Antonovics J, eds) Oxford Univ Press, New York, 225-249

Ginsburger-Vogel T, Carre-Lecuyer M, Fried-Montaufier MC (1980) Transmission expérimentale de la thélygénie liée à l'intersexualité chez Orchestia gammarellus (Pallas). Analyse des phénotypes sexuels dans les descendances de femelles normales transformées en femelles thélygènes. Arch Zool Exp Gén 122, 261-270

Hickey DA (1982) Selfish DNA: a sexually-transmitted nuclear parasite. Genetics $101,519-531$

Juchault P, Legrand JJ (1972) Croisement de néo-mâles expérimentaux chez Armadillidium vulgare Latr (Crustacé, Isopode, Oniscoïde). Mise en évidence d'une hétérogamétie femelle. CR Acad Sci Paris, 274, 1387-1389

Juchault P, Legrand JJ (1981a) Contribution à l'étude qualitative et quantitative des facteurs contrôlant le sexe dans les populations du Crustacé Isopode terrestre Armadillidium vulgare Latr. II. Populations hébergeant le facteur féminisant $\mathrm{F}$ (bactérie intracytoplasmique). Arch Zool Exp Gén 122 (1), 65-74

Juchault P, Legrand JJ (1981b) Contribution à l'étude qualitative et quantitative des facteurs contrôlant le sexe dans les populations du Crustacé Isopode terrestre Armadillidium vulgare Latr. III. Populations n'hébergeant pas le facteur féminisant F. Arch Zool Exp Gén 122 (2), 117-131

Juchault P, Legrand JJ (1989) Sex determination and monogeny in terrestrial isopods Armadillidium vulgare (Latreille, 1804) and Armadillidium nasatum (Budde-Lund, 1885). Monit Zool Ital (NS) Monogr 4, 359-375

Juchault P, Mocquard JP (1989) Effets de l'inoculation d'une bactérie endocellulaire féminisante sur la croissance et la reproduction des femelles du Crustacé Oniscoïde A vulgare Latr. Conséquences possibles sur l'évolution des populations. Crustaceana $56(1), 83-92$

Juchault P, Legrand JJ, Mocquard JP (1980) Contribution à l'étude qualitative et quantitative des facteurs contrôlant le sexe dans les populations du Crustacé 
Isopode terrestre Armadillidium vulgare Latr. I. La population de Niort (DeuxSèvres). Arch Zool Exp Gén 121 (1), 3-27

Legrand JJ, Juchault P (1984) Nouvelles données sur le déterminisme génétique et épigénétique de la monogénie chez le Crustacé Isopode terrestre Armadillidium vulgare Latr. Gen Sél Evol 16, 57-84

Legrand JJ, Juchault P, Mocquard JP (1974) Analyse préliminaire de l'intersexualité féminisante chez le Crustacé Armadillidium vulgare Latr (Isopode Oniscoïde). CR Acad Sci Paris 278, 2979-2982

Legrand JJ, Legrand-Hamelin E, Juchault P (1987) Sex determination in crustacea. Biol Rev 62, 439-470

Martin G, Juchault P, Legrand JJ (1973) Mise en évidence d'un micro-organisme intracytoplasmique symbiote de l'Oniscoïde Armadillidium vulgare $\mathrm{L}$, dont la présence accompagne l'intersexualité ou la féminisation totale des mâles génétiques de la lignée thélygène. CR Acad Sci Paris 276, 2313-2316

Nardon P, Grenier AM (1989) Symbiosis as an important factor for the growth and the evolution of the populations of Sitophilus oryzae L (Coleoptera, Curculionidae). In: Endocytobiology IV (Nardon $\mathrm{P}$ et al, eds) INRA, Paris, 369-372

Rigaud T, Juchault P (1992) Genetic control of the vertical transmission of a cytoplasmic sex factor in Armadillitium vulgare Latr (Crustacea, Oniscidea). Heredity 68, 47-52

Rigaud T, Juchault P, Mocquard JP (1991) Experimental study of temperature effects on sex ratio of broods in terrestrial crustacea Armadillidium vulgare Latr. Possible implication in natural populations. J Evol Biol 4, 603-617

Rigaud T, Souty-Grosset C, Raimond R, Mocquard JP, Juchault P (1991) Feminizing endocytobiosis in the terrestrial crustacean Armadillidium vulgare Latr (Isopoda): recent acquisitions. Endocytobiosis Cell Res 7, 259-273

Skinner SW (1983) Extrachromosomal sex ratio factors in the parasitoid wasp, Nasonia (=Mormoniella) vitripennis. Ph $\mathrm{D}$ thesis, University of Utah, Salt Lake City, UT

Stevens L, Wade MJ (1990) Cytoplasmically inherited reproductive incompatibility in Tribolium flour beetles: the rate of spread and effect on population size. Genetics $124,367-372$

Sutton SL, Hassal M, Willows R, David RC, Grund A, Sunderland KD (1984) Life histories of terrestrial isopods: a study of intra- and interspecific variation. Symp Zool Soc Lond 53, 269-294

Taylor DR (1990) Evolutionary consequences of cytoplasmic sex ratio distorters. Evol Ecol 4, 235-248

Vandel A (1962) Isopodes Terrestres: Faune de France (66). Paul Chevalier, Paris, part 2

Werren JH, Skinner SW, Charnov EL (1981) Paternal inheritance of a daughterless sex ratio factor. Nature (Lond) 293, 467-468 